\title{
ॠUSGS
}

Collections Management Plan for the U.S. Geological Survey Woods Hole Coastal and Marine Science Center Samples Repository
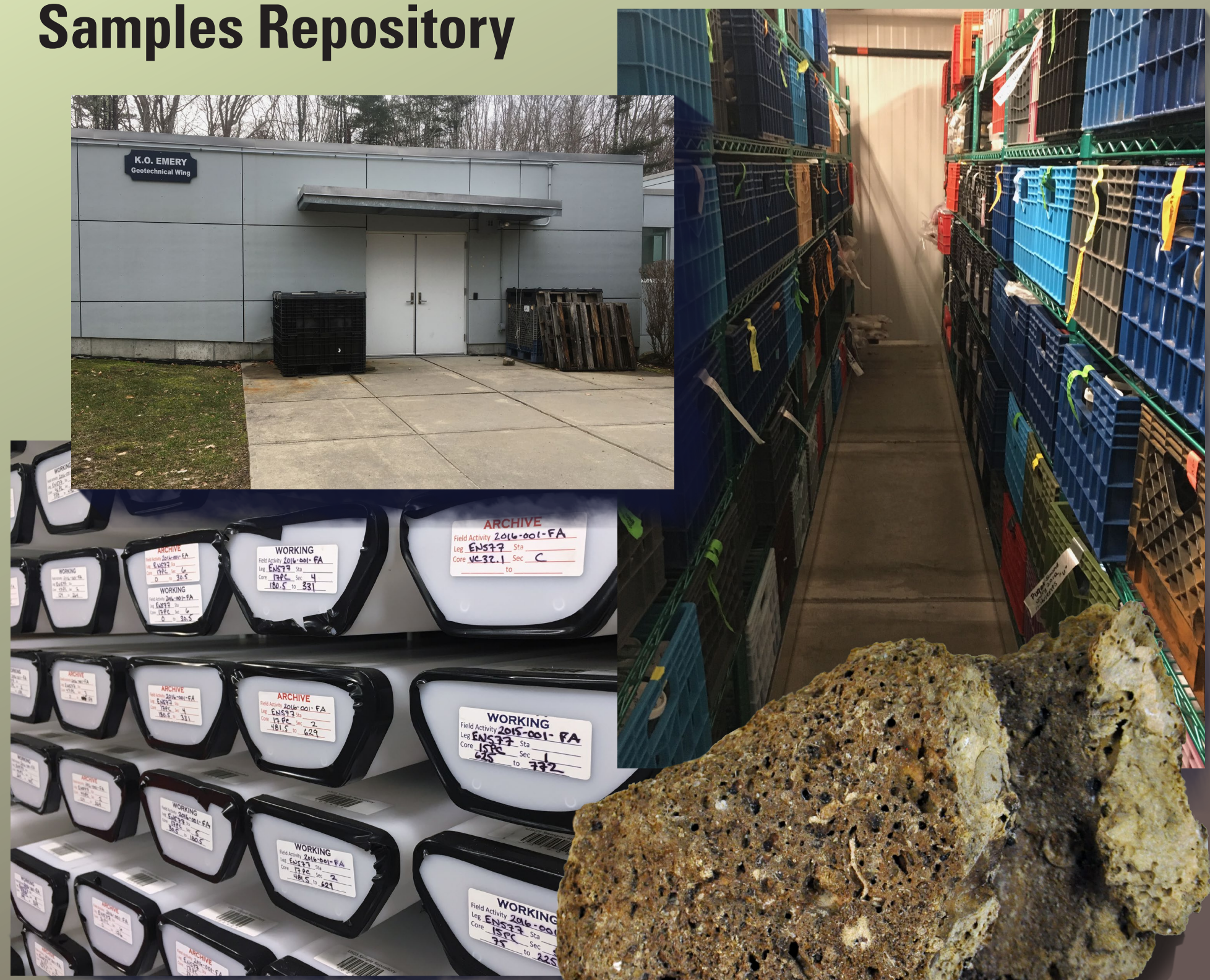

Open-File Report 2018-1100

U.S. Department of the Interior U.S. Geological Survey 
Cover. Upper left: The K.O. Emery Geotechnical Wing of the U.S. Geological Survey offices in Woods Hole, Massachusetts. Upper right: View of rolling storage racks inside the walk-in freezer. Lower right: Sample NA052-039 from USGS field Activity 2014-018-FA. Lower left: Close up look at split cores in D-tubes in the walk-in refrigerator. Photographs by Brian Buczkowski, U.S. Geological Survey. 


\section{Collections Management Plan for the U.S. Geological Survey Woods Hole Coastal and Marine Science Center Samples Repository}

By Brian J. Buczkowski

Open-File Report 2018-1100 


\title{
U.S. Department of the Interior \\ RYAN K. ZINKE, Secretary
}

\section{U.S. Geological Survey James F. Reilly II, Director}

\author{
U.S. Geological Survey, Reston, Virginia: 2018 \\ Supersedes USGS Open-File Report 2006-1187
}

For more information on the USGS —-the Federal source for science about the Earth, its natural and living resources, natural hazards, and the environment-visit https://www.usgs.gov or call 1-888-ASK-USGS.

For an overview of USGS information products, including maps, imagery, and publications, visit https://store.usgs.gov.

Any use of trade, firm, or product names is for descriptive purposes only and does not imply endorsement by the U.S. Government.

Although this information product, for the most part, is in the public domain, it also may contain copyrighted materials as noted in the text. Permission to reproduce copyrighted items must be secured from the copyright owner.

Suggested citation:

Buczkowski, B.J., 2018, Collections management plan for the U.S. Geological Survey Woods Hole Coastal and Marine Science Center Samples Repository: U.S. Geological Survey Open-File Report 2018-1100, 12 p., https://doi.org/10.3133/ofr20181100. [Supersedes USGS Open-File Report 2006-1187.]

ISSN 2331-1258 (online) 


\section{Preface}

The U.S. Geological Survey Woods Hole Coastal and Marine Science Center Samples Repository was formed in late 2002, beginning as a dedicated effort to catalog and organize scientific samples collected by researchers at the Woods Hole Science Center, as it was then known. U.S. Geological Survey Open-File Report 2006-1187, "Archival Policies and Collections Database for the Woods Hole Science Center's Marine Sediment Samples," was released in 2007. Open-File Report 2006-1187 documents the collections management policies and procedures initially developed by the Samples Repository as well as provides a collections inventory that represents the samples that were available through the Repository at that point in time.

The Samples Repository has since grown as research and field work have continued, with new facilities built to house the sample collections, improved collections management procedures developed, and new acquisitions accepted into the collections. This report provides an overview of the Woods Hole Coastal and Marine Science Center Samples Repository facilities, describes of the types of samples preserved and managed there, and details the collections management procedures implemented by the Samples Repository to ensure the preservation and usefulness of these samples for future research.

This report, as well as the companion data release, "Collections Inventory for the U.S. Geological Survey Woods Hole Coastal and Marine Science Center Samples Repository," supersedes the information and inventory provided by U.S. Geological Survey Open-File Report 2006-1187. 


\section{Acknowledgments}

The completeness, clarity, and usability of this report have benefitted from critical reviews by Betty Adrian, Mike Torresan, Zafer Defne, and Lindsay Powers, all at the U.S. Geological Survey. 


\section{Contents}

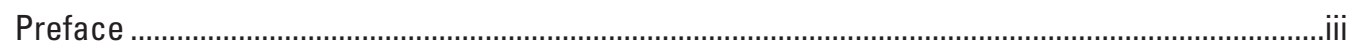

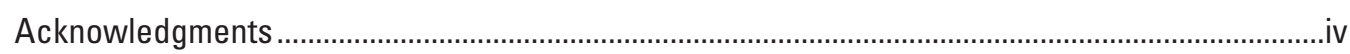

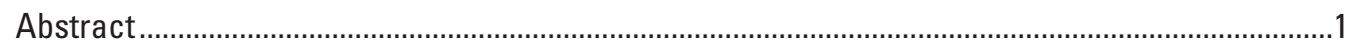

Introduction to the Woods Hole Coastal and Marine Science Center Samples Repository..............1

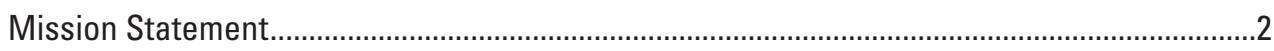

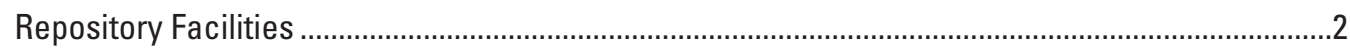

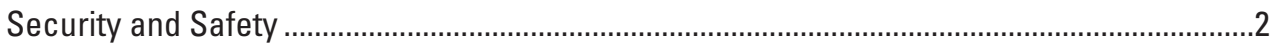

Types of Samples Preserved and Maintained in the Samples Repository........................................

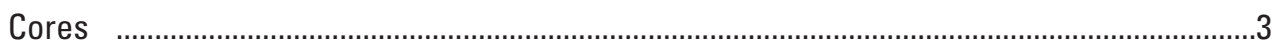

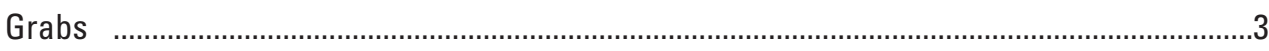

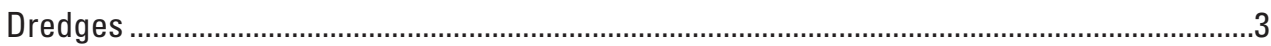

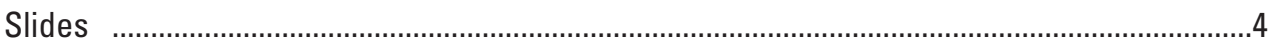

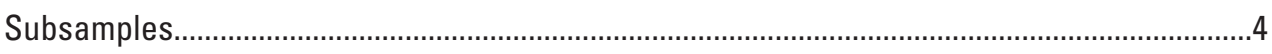

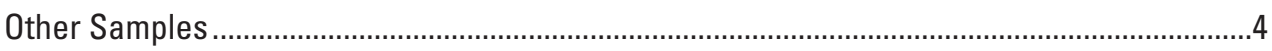

Sample Acquisition ................................................................................................................

Reserving Storage Space...............................................................................................

Evaluating and Accepting Samples Submitted to the Repository ..............................................

Health and Safety.......................................................................................................

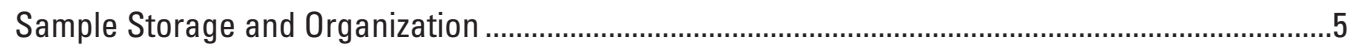

Accessing Samples and Scientific Collections ……..............................................................

Requesting Samples....................................................................................................

Notification of Request Status........................................................................................

Conditions of an Approved Loan .................................................................................... 8

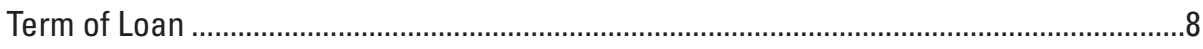

Use of Samples and Scientific Collections ...................................................................

Alteration of Samples..............................................................................................

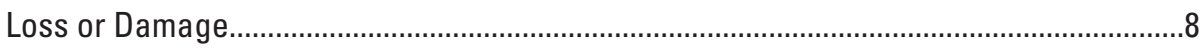

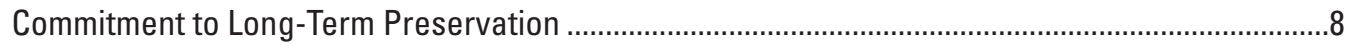

Transfer of Custody to the National Museum of Natural History................................................

Collections Management Across the U.S. Geological Survey .......................................................

The USGS Collections Steering Committee.......................................................................

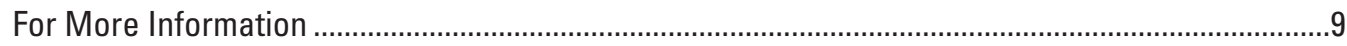

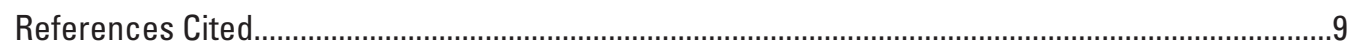

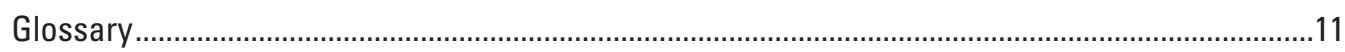




\section{Figures}

1. Photograph showing storage vans, referred to as the "Freezer Farm," outside the U.S. Geological Survey offices in Woods Hole, Massachusetts (2004) 1

2. Photograph showing the K.O. Emery Geotechnical Wing of the U.S. Geological Survey offices in Woods Hole, Massachusetts (2018)

3. Photograph showing rolling storage racks installed in the U.S. Geological Survey Woods Hole Coastal and Marine Science Center Samples Repository walk-in freezer......

4. Photograph showing d-tubes containing split cores are labeled and archived in the U.S. Geological Survey Woods Hole Coastal and Marine Science Center Samples Repository walk-in refrigerator.

5. Decision tree used to evaluate scientific collections considered for inclusion in the U.S. Geological Survey Woods Hole Coastal and Marine Science Center Samples Repository

6. Screen capture showing geographic information system interface available to search the collections inventory for the U.S. Geological Survey Woods Hole Coastal and Marine Science Center Samples Repository.

\section{Tables}

1. Available storage locations in the U.S. Geological Survey Woods Hole Coastal and Marine Science Center Samples Repository and the abbreviated codes used to identify these locations.

2. U.S. Geological Survey Woods Hole Coastal and Marine Science Center Samples Repository collections inventory search fields and their definitions 


\section{Conversion Factors}

U.S. customary units to International System of Units

\begin{tabular}{ccc}
\hline Multiply & By & To obtain \\
\hline square foot $\left(\mathrm{ft}^{2}\right)$ & 0.09290 & square meter $\left(\mathrm{m}^{2}\right)$ \\
\hline
\end{tabular}

Temperature in degrees Celsius $\left({ }^{\circ} \mathrm{C}\right)$ may be converted to degrees Fahrenheit $\left({ }^{\circ} \mathrm{F}\right)$ as ${ }^{\circ} \mathrm{F}=\left(1.8 \times{ }^{\circ} \mathrm{C}\right)+32$.

Temperature in degrees Fahrenheit $\left({ }^{\circ} \mathrm{F}\right)$ may be converted to degrees Celsius $\left({ }^{\circ} \mathrm{C}\right)$ as ${ }^{\circ} \mathrm{C}=\left({ }^{\circ} \mathrm{F}-32\right) / 1.8$.

\section{Abbreviations}

$\begin{array}{ll}\text { CMGDS } & \text { Coastal and Marine Geoscience Data System } \\ \text { CMGP } & \text { Coastal and Marine Geology Program } \\ \text { CSC } & \text { Collections Steering Committee } \\ \text { FAN } & \text { field activity number } \\ \text { GCMS } & \text { Geologic Collections Management System } \\ \text { NGGDPP } & \text { National Geological and Geophysical Data Preservation Program } \\ \text { NMNH } & \text { National Museum of Natural History (Smithsonian Institution) } \\ \text { PI } & \text { principal investigator } \\ \text { USGS } & \text { U.S. Geological Survey } \\ \text { WHCMSC } & \text { Woods Hole Coastal and Marine Science Center } \\ \text { WHOI } & \text { Woods Hole Oceanographic Institution }\end{array}$





\title{
Collections Management Plan for the U.S. Geological Survey Woods Hole Coastal and Marine Science Center Samples Repository
}

\author{
By Brian J. Buczkowski
}

\begin{abstract}
Since 2002, the Woods Hole Coastal and Marine Science Center Samples Repository has been supporting research by providing secure storage for geological, biological, and geochemical samples; maintaining organization and an active inventory of these sample collections; and providing researchers access to these scientific collections for study and reuse.

Over the years, local storage facilities have changed and new collections management strategies have been adapted as sample collections have grown and as research programs and focuses have shifted. The commitment of the Samples Repository to preserve and provide physical samples for future research, however, has remained the same. This report documents the collections management plan developed and implemented by the Woods Hole Coastal and Marine Science Center Samples Repository to manage its scientific collections.
\end{abstract}

\section{Introduction to the Woods Hole Coastal and Marine Science Center Samples Repository}

Located in Woods Hole, Massachusetts, the U.S. Geological Survey (USGS) Coastal and Marine Science Center (WHCMSC) has been a member of the Woods Hole scientific community since 1962 . From the beginning, samples ${ }^{1}$ collected by USGS scientists in this office have provided invaluable insight into the nature and character of coastal, estuarine, and nearshore marine environments, as well as the sea floora region that remains to this day one of the least explored places on the Earth. Many of these samples are unique and irreplaceable because of either the great difficulty and expense in their collection or the changing nature of these locations.

Early in its history, WHCMSC, then known as the Branch of Atlantic Marine Geology, established an agreement with the Woods Hole Oceanographic Institution (WHOI) to co-locate

${ }^{1}$ Terms in bold are defined in the glossary.
USGS collections of marine cores, dredged rocks, and surface sediments within WHOI's Core Lab repository. This was done to preserve these samples for further investigations and ensure that the scientific legacy of USGS research will not be lost.

D-tubes containing split cores, subsamples of dredges, and sediment grab samples (grabs) collected by USGS scientists are still housed in the WHOI repository; the cooperative agreement between the two institutions continues to this day. In addition to the protected storage provided by WHOI, the USGS acquired a number of outdoor climate-controlled vans to store grab samples, subsamples, split and whole cores, and smaller sample collections (see section "Types of Collections Preserved and Maintained in the Samples Repository" for detailed descriptions of these sample types) in refrigerated, freezing, and ambient temperatures (fig. 1). These outdoor vans became collectively known as the "Freezer Farm." Upon acquiring these storage units, the USGS took steps to create

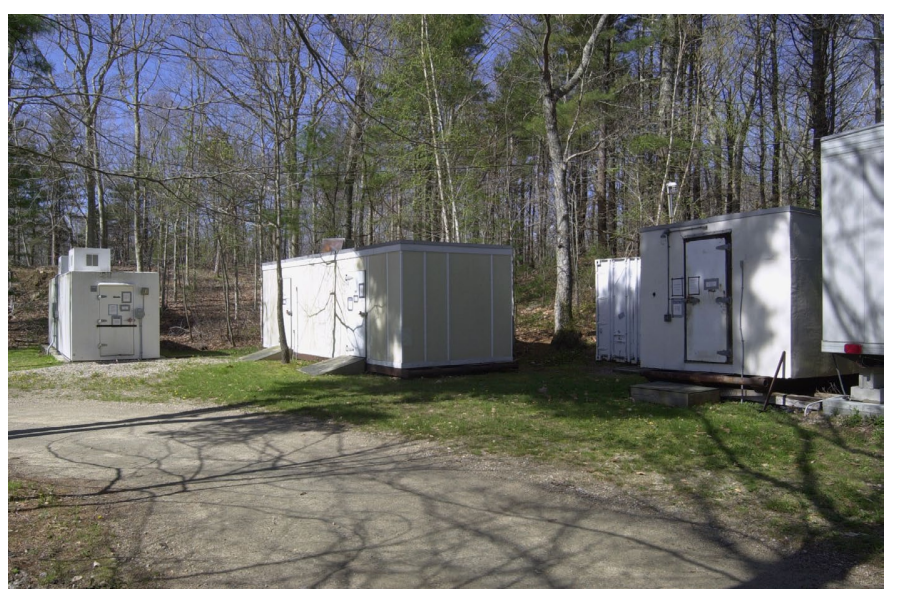

Figure 1. Storage vans, referred to as the "Freezer Farm," sit outside the U.S. Geological Survey offices in Woods Hole, Massachusetts (2004). Photograph by Brian Buczkowski, U.S. Geological Survey. 
and maintain order among the vans and the samples housed within them.

The WHCMSC Samples Repository (hereafter referred to as the "Samples Repository") was officially formed in 2002 to formally catalog and organize these geological, geochemical, and biological scientific collections and to establish policies and procedures for their preservation and access. Since its inception, the Samples Repository has seen developments in collections management strategies, as well as the construction of the current storage facility, the K.O. Emery Geotechnical Wing (fig. 2).

\section{Mission Statement}

The mission of the Samples Repository is to

1. serve as the USGS repository for geological, biological, and geochemical samples collected through field research sponsored by the WHCMSC,

2. provide long-term storage of these samples collected byt WHCMSC scientists and affiliated researchers under controlled conditions to ensure optimum preservation, and

3. maintain an inventory of sample collections stored in the Samples Repository and promote the secondary usage of the sample material in its care by the scientific community.

The Samples Repository provides secure storage, processing, and resampling services to USGS scientists and researchers from government and academic institutions investigating the history, nature, and physical properties of geological, biological, and geochemical materials collected from coastal, marine, and nearshore environments. Legacy collections in the Samples Repository continue to be a resource for research and scientific investigation as a result of preservation

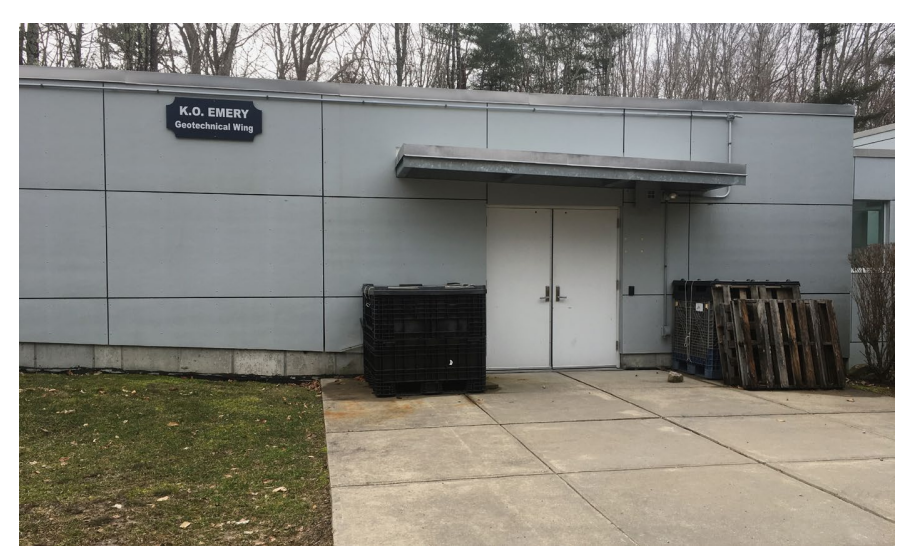

Figure 2. The K.O. Emery Geotechnical Wing of the U.S. Geological Survey offices in Woods Hole, Massachusetts (2018). Photograph by Brian Buczkowski, U.S. Geological Survey. efforts and access to the samples through the collections inventory (Buczkowski and others, 2018).

\section{Repository Facilities}

The Samples Repository is collocated on WHOI's Quissett Campus in Woods Hole, Mass. The K.O. Emery Geotechnical Wing serves as the primary storage location for all geological, biological, and geochemical samples either collected through research sponsored by WHCMSC or in the permanent custody of the USGS. Local storage facilities within the Geotechnical Wing consist of walk-in refrigerated and frozen cold rooms, ambient storage space for dry samples, and an analysis and sampling facility.

The refrigerated cold room measures 774.5 square feet and maintains a storage temperature of 39 degrees Fahrenheit (4 degrees Celsius). The freezer, measuring 420 square feet, maintains a storage temperature of -4 degrees Fahrenheit ( -20 degrees Celsius). These temperature-controlled and monitored facilities have been partially built into a hillside to maximize insulation and efficiency, and they are designed to exclude the ambient environment, as fluctuations in air temperature and humidity can degrade the viability of the samples for scientific research and promote the growth of mold on and in the samples. Both rooms are equipped with rolling storage racks, which maximize available space for sediment and subsample storage and allow for future expansion as collections grow (fig. 3). Core racks and mobile storage carts are also available to organize and store samples in these rooms.

\section{Security and Safety}

Doors to the walk-in refrigerator and freezer are locked, and access is permitted only with the use of a proximity pass system administered by personnel at the WHCMSC. Key pass swipes are monitored and recorded to track personnel going into and out of these spaces. Refrigerator and freezer doors are operable from the inside with a proximity pass scanner and a "Push to Exit" button - measures designed to prevent anyone from being locked in. Panic buttons are located in each of the cold rooms in the event of injury or emergency. These panic buttons sound an alarm in the WHCMSC Gundersen Wing lobby. Users of the facilities are instructed to press and hold the panic button until help arrives; the alarm will only sound while the button is pushed.

Protective gear worn in the freezers is necessary for any activity exceeding 2 minutes. Steel-toed thermal boots, thermal union suits, glove liners, gloves, facemasks, and several types of hats and hoods are available to project staff accessing and working in these facilities. Detailed safety information, as well as updated job hazard analysis reports for facilities and equipment in the Samples Repository, is available through local WHCMSC safety officers. 


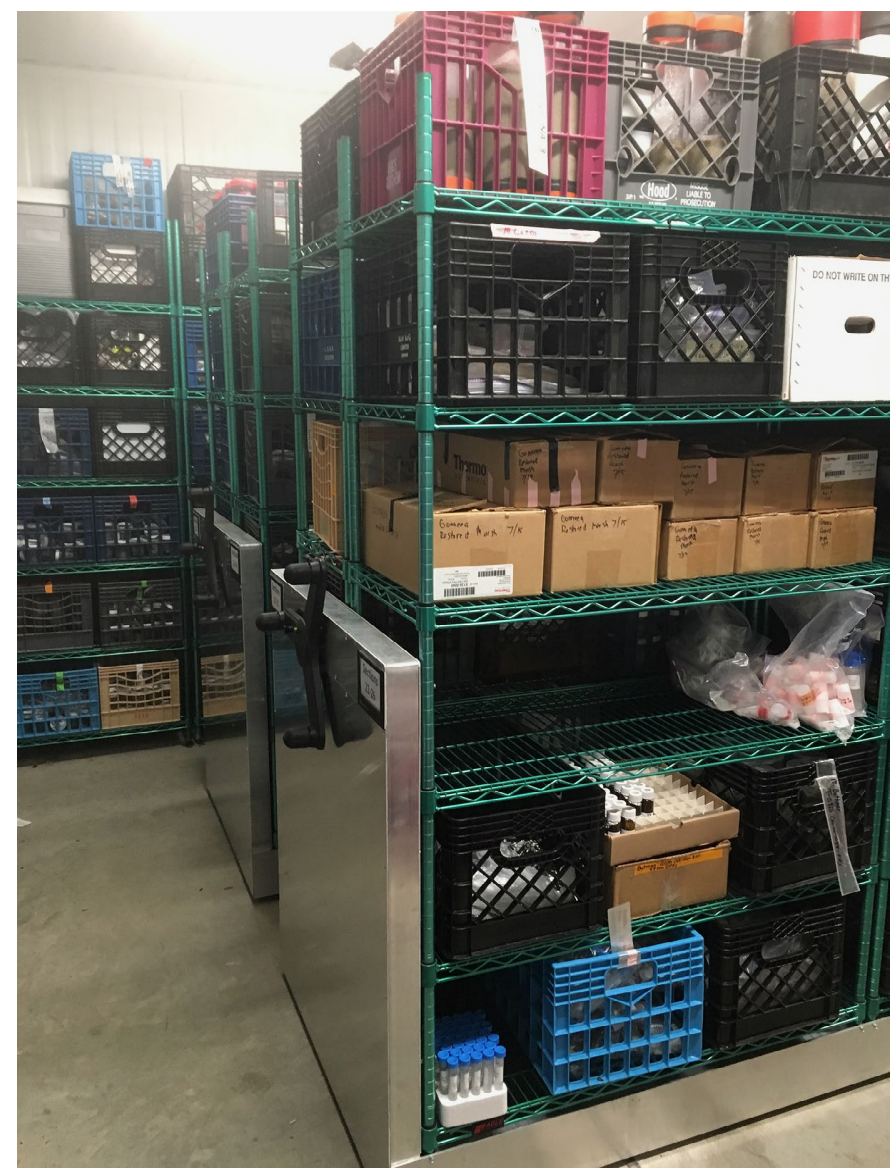

Figure 3. Rolling storage racks installed in the U.S. Geological Survey Woods Hole Coastal and Marine Science Center Samples Repository walk-in freezer. Photograph by Brian Buczkowski, U.S. Geological Survey.

\section{Types of Samples Preserved and Maintained in the Samples Repository}

The Samples Repository preserves geological, biological, and geochemical samples collected through research sponsored by the WHCMSC or given into the custody of the USGS. The bulk of these sample collections consist of marine sediment cores, grab samples, and dredged rock samples. Categories are defined by the devices with which samples were collected - corers, grab samplers, and dredges (see Hopkins, 1964, for detailed descriptions of many of these devices); categories also include sample slides and subsamples, which are derivative products from these cores, grabs, and dredges. The Samples Repository maintains small collections of other sample types, such as corals, water samples, and peel samples, which are also accounted for in the collections inventory.

\section{Cores}

Cores are cylindrical samples of rock or unconsolidated sediment, collected vertically through the surface of the sea floor and into the substrate beneath. A core, when collected perpendicular to the stratigraphic layers below the surface, provides a cross-section of the depositional history at the specific location of collection.

Most cores are split in half longitudinally by researchers to view the sediment and character of the core for descriptions and to provide access for resampling. These split halves are stored in D-tubes horizontally in the Samples Repository (fig. 4).

\section{Grabs}

Grab samples consist of the unconsolidated substrate found on the surface of the sea floor. These samples usually consist of loose sediment, as well as any seashells, shell fragments, or other components of the sea floor captured by the grab device. Grab samples of loose sediment and shell material are bagged after collection and housed in refrigerated storage, or they are dried and stored in ambient temperature and humidity conditions in the Samples Repository.

\section{Dredges}

Rock samples plucked from the seabed by dredges towed behind research vessels are available in the Samples Repository. These samples are boxed and stored in ambient environmental conditions, either in the Samples Repository core laboratory or in long-term storage at WHCMSC's Marine Operations Facility.

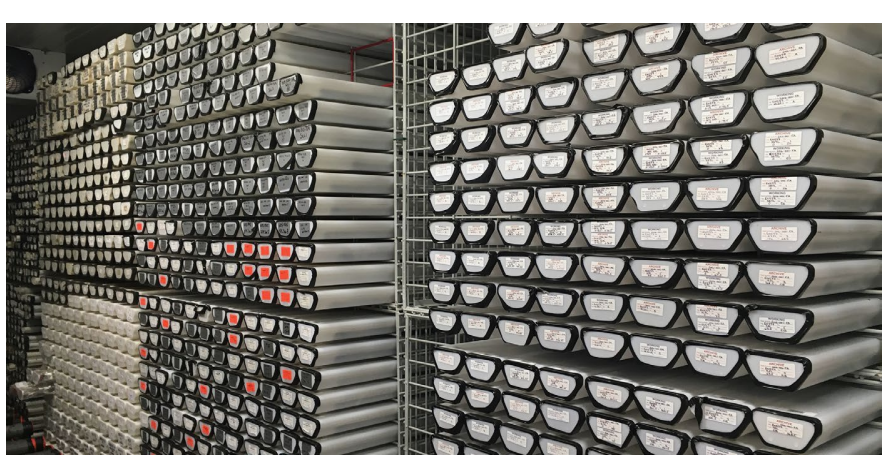

Figure 4. D-tubes containing split cores are labeled and archived in the U.S. Geological Survey Woods Hole Coastal and Marine Science Center Samples Repository walk-in refrigerator. Photograph by Brian Buczkowski, U.S. Geological Survey. 


\section{Slides}

The Samples Repository maintains a collection of slides created for microscopic analyses. This slide collection consists of foraminifera and diatom tests picked by paleontologists and exploration geologists from marine and terrestrial sediment cores, thin sections of geological sample material, and smear slides of unconsolidated marine sediment.

\section{Subsamples}

Subsamples are samples taken from cores, grabs, and dredges that were previously described and analyzed. These subsamples may often be used again for further research and investigation. Subsamples are retained by the Samples Repository and stored according to their long-term preservation needs. They are available for further study upon request.

\section{Other Samples}

WHCMSC personnel may occasionally collect various other sample types and materials in the course of research. These samples are preserved and inventoried in the Samples Repository. They include coral skeletons, water samples, and peel samples and are available for research upon request.

\section{Sample Acquisition}

The majority of the samples and scientific collections preserved and maintained by the Samples Repository come from field activities sponsored by the WHCMSC. Field activities originating from all three USGS Coastal and Marine Geology Program (CMGP) science centers (Woods Hole, Mass., St. Petersburg, Florida, and Santa Cruz, California), as well as activities with participation from CMGP personnel, are assigned field activity numbers (FANs) by USGS data managers using the field activity management and data tracking tool, Compass. FAN registration includes documentation of all participating personnel, scientific objectives, equipment for acquiring data and samples, dates, and location of operation. These FANs are associated with every sample collected in the field and are used to identify key pieces of information required to catalog and organize them (see section "Evaluating and Accepting Samples Submitted to the Repository"). Compass is only accessible to USGS personnel in CMGP; however, field activity information is available online to the public through the USGS Coastal and Marine Geoscience Data System (CMGDS): https://cmgds.marine.usgs.gov/.

Often legacy collections that were collected by CMGP researchers no longer with the USGS or were collected as part of past research projects, discovered stashed away in offices and other locations outside the Samples Repository, can be traced to the field activity they came from. Information pertaining to collection and research history can be gathered by researching the available information in Compass, in the CMGDS, and from available data libraries (List and others, 2015). This information can be used to incorporate these legacy collections into the institutional collections managed by the Samples Repository.

Upon discovery, legacy collections may be determined to be in poor condition. Samples that have deteriorated or been damaged beyond any useful value for further scientific study, or are lacking essential information to identify their condition and origin will not be accepted into the Samples Repository.

Samples that do not have an associated FAN, but which are donated into the permanent custody of the USGS and are accompanied by sufficient information to identify them and their collection history, may be considered for inclusion into the Samples Repository. If these samples are accepted for inclusion, a new FAN is registered by using available information; these donated collections are evaluated in the same manner as legacy collections.

\section{Reserving Storage Space}

For samples originating from field activities sponsored by the WHCMSC, it is the responsibility of project scientists to ensure that there is storage space available to accommodate the incoming samples prior to any sample collection field activity. The principal investigator (PI) or collecting scientist will contact the Samples Repository Curator of Geologic Collections (hereafter referred to as "Curator") with information pertaining to any sample collection at least two weeks before the field activity begins. The scientist will provide the Curator an approximate number of samples to be recovered and the type of storage required (ambient, refrigerated, or frozen). The Curator then makes arrangements to house the incoming samples. During this two-week period, the Curator locates and reserves space for the new samples and notifies the project scientist where the samples will be stored.

\section{Evaluating and Accepting Samples Submitted to the Repository}

The WHCMSC K.O. Emery Geotechnical Wing provides secure storage for working collections: suites of samples actively used for scientific research which may be subject to consumptive analysis and are not initially intended for longterm preservation due to their expendable nature; as well as institutional collections: samples determined to have longterm scientific value to the USGS that should be preserved to ensure their scientific integrity and availability for future scientific research. Scientific collections are evaluated, and periodically re-evaluated, for their research potential, possible reclassification, appropriateness for acceptance and retention in the Samples Repository, and inclusion into the collections inventory. Those samples and collections with information (metadata) insufficient to identify them and their collection 
history, and those that are not deemed appropriate for longterm retention on the basis of their iconic, historic, or further scientific value (which may be the case for some working collections), will not be formally accepted into the Samples Repository's institutional collections, nor included in the collections inventory.

Sufficient information that identifies samples and scientific collections is defined in the USGS Geologic Collections Management System (GCMS) in what is called the 4-point standard (Geologic Materials Repository Working Group, 2015). In order to be considered for acceptance into the Samples Repository, samples must have accompanying metadata that address the four necessary components of the 4-point standard:

1. A sample name or some other identifier that is unique to that sample in the context of the field activity or greater collection to which it belongs;

2. Information about the specific location of collection, preferably as geographic coordinates (however, site names and geographic features can be used to approximate collection site locations) in order to graphically display collection origins for the samples managed in the Samples Repository; in the case of samples collected at sea, which most of the materials in the Samples Repository are, water depths recorded at the time of collection are also required;

3. Any and all available information relating to the field activity, cruise, or expedition the sample came from (at the most basic, the Samples Repository requires the name of the PI or collecting scientist); and

4. The date of collection for each sample.

For samples without an associated FAN, these four pieces of information can be used to initiate a FAN request. This newly assigned FAN is used to link samples in the collections inventory to all available information about them provided through CMGDS. Figure 5 shows the decision tree, modified from the one presented in the USGS GCMS (Geologic Materials Repository Working Group, 2015, fig. 3), used in the Samples Repository to evaluate incoming samples and scientific collections.

Samples in the Samples Repository will be periodically re-evaluated to ensure their continued preservation and usefulness for ongoing and future research. Re-evaluation will take into consideration storage availability and limitations, as well as the physical condition of the samples, and will be used to determine the appropriate disposition of the materials and to minimize the loss or destruction of otherwise valuable samples.

The recommended method to submit collections metadata to the Samples Repository is to electronically send all information directly to the Curator. A Microsoft Excel template is available through the Samples Repository Collections Management web page and can be used to organize and document this information: https://woodshole.er.usgs.gov/operations/ $\mathrm{ia} / \mathrm{samprepo/collectionsmanagement.html.} \mathrm{This} \mathrm{metadata} \mathrm{is}$ then formatted into a collections inventory database (Buczkowski and others, 2018), which provides search access to the Samples Repository's holdings through the Samples Repository inventory search page:

https://woodshole.er.usgs.gov/operations/ia/samprepo/ searchcat.html.

\section{Health and Safety}

Samples or suites of samples from environmental studies may contain preservatives, such as formalin or sodium azide, or trace amounts of heavy metals, such as mercury, that may be harmful to humans. Any samples submitted to the Samples Repository that may contain any concentration of toxic preservatives, heavy metal content, asbestos, radioactivity, or any other suspected hazard, must be explicitly identified as such before the materials are accepted. The Curator consults with local safety officers on the appropriateness of retaining these materials onsite, or, if needed, determine if these sample collections would be better kept elsewhere to prevent possible harm through exposure to toxic elements.

\section{Sample Storage and Organization}

Available storage in the Samples Repository is divided into six locations. Each location has been assigned an identifying code or word (table 1).

Specific storage within each space in the K.O. Emery Geotechnical Wing (RE01, FR01, and LAB) is further broken down to specify the precise location of sample collections, facilitating retrieval. Individual shelving units on the rolling storage racks, as well as stationary shelves, core racks, and mobile storage carts, have been assigned section numbers. Each shelf is numbered, starting at 01 on the top shelf and continuing downward. Visit the Samples Repository facilities page (https://woodshole.er.usgs.gov/operations/ia/samprepo/ facilities.html) for updated information on the current layout and storage schematics of the K.O. Emery Geotechnical Wing.

These three components (storage location, section number, and shelf number [where available]) are combined into a single storage identification number, which is assigned to each inventoried sample in the Samples Repository. As an example, samples stored in refrigerated space, in section 02 , on the third shelf from the top, would be given the location identifier RE01.02.03.

The Samples Repository uses barcode labels to identify samples, coordinate storage, and aid in retrieving samples. Barcodes are affixed to various containers in the Samples Repository and are related to individual entries in the collections inventory. Some containers may hold only one sample. For example, D-tubes may contain only one split half of a core. Other containers, such as milk crates and boxes, may 


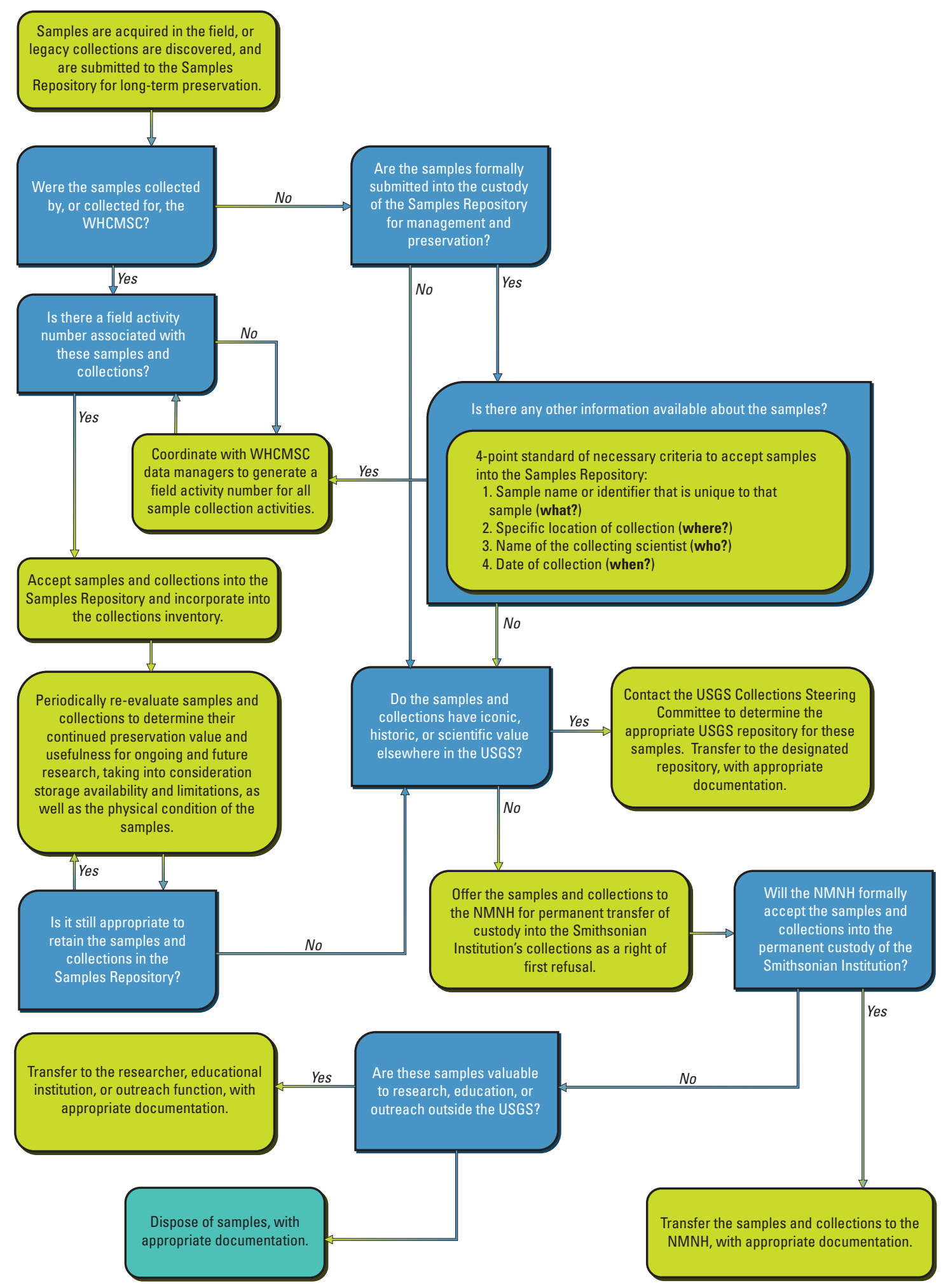

Figure 5. Decision tree used to evaluate scientific collections considered for inclusion in the U.S. Geological Survey Woods Hole Coastal and Marine Science Center Samples Repository, modified from figure 3 in the Geological Collections Management System (Geologic Materials Repository Working Group, 2015) and figure 1 in the collections management plan for the U.S. Geological Survey Woods Hole Coastal and Marine Science Center Data Library (List and others, 2015). WHCMSC, Woods Hole Coastal and Marine Science Center; USGS, U.S. Geological Survey; NMNH, Smithsonian Institution National Museum of Natural History. 
Table 1. Available storage locations in the U.S. Geological Survey Woods Hole Coastal and Marine Science Center Samples Repository and the abbreviated codes used to identify these locations.

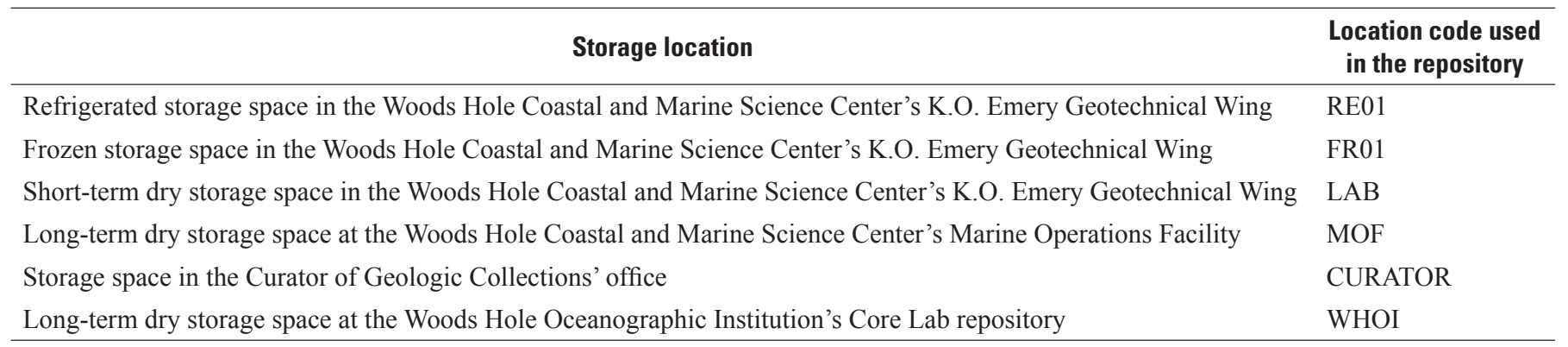

contain numerous samples. The Curator can use barcodes in the collections inventory to track the physical locations of individual samples in the Samples Repository as well as those on loan.

\section{Accessing Samples and Scientific Collections}

The responsibility of the Samples Repository, and the Curator, is to provide samples and scientific collections for research and reuse and to oversee their preservation and security. Sample collections can be searched by using the inventory search interface (fig. 6) provided online at https://woodshole. er.usgs.gov/operations/ia/samprepo/searchcat.html (Buczkowski and others, 2018).
The inventory search interface allows for search and selection either through a geographic information system (GIS) display or through a web form for searching known criteria (table 2). Both options query and export selected portions of the collections inventory. Search results are downloaded as comma-separated value (CSV) files and come with customized metadata.

\section{Requesting Samples}

Sample request forms, which include information about the Samples Repository's policies on loan requests, resampling, and data return, are available through the Request Samples page (https://woodshole.er.usgs.gov/operations/ ia/samprepo/request.html). The Samples Repository makes every effort to fulfill sample requests and aid in research whenever possible. All transactions are made and requests are

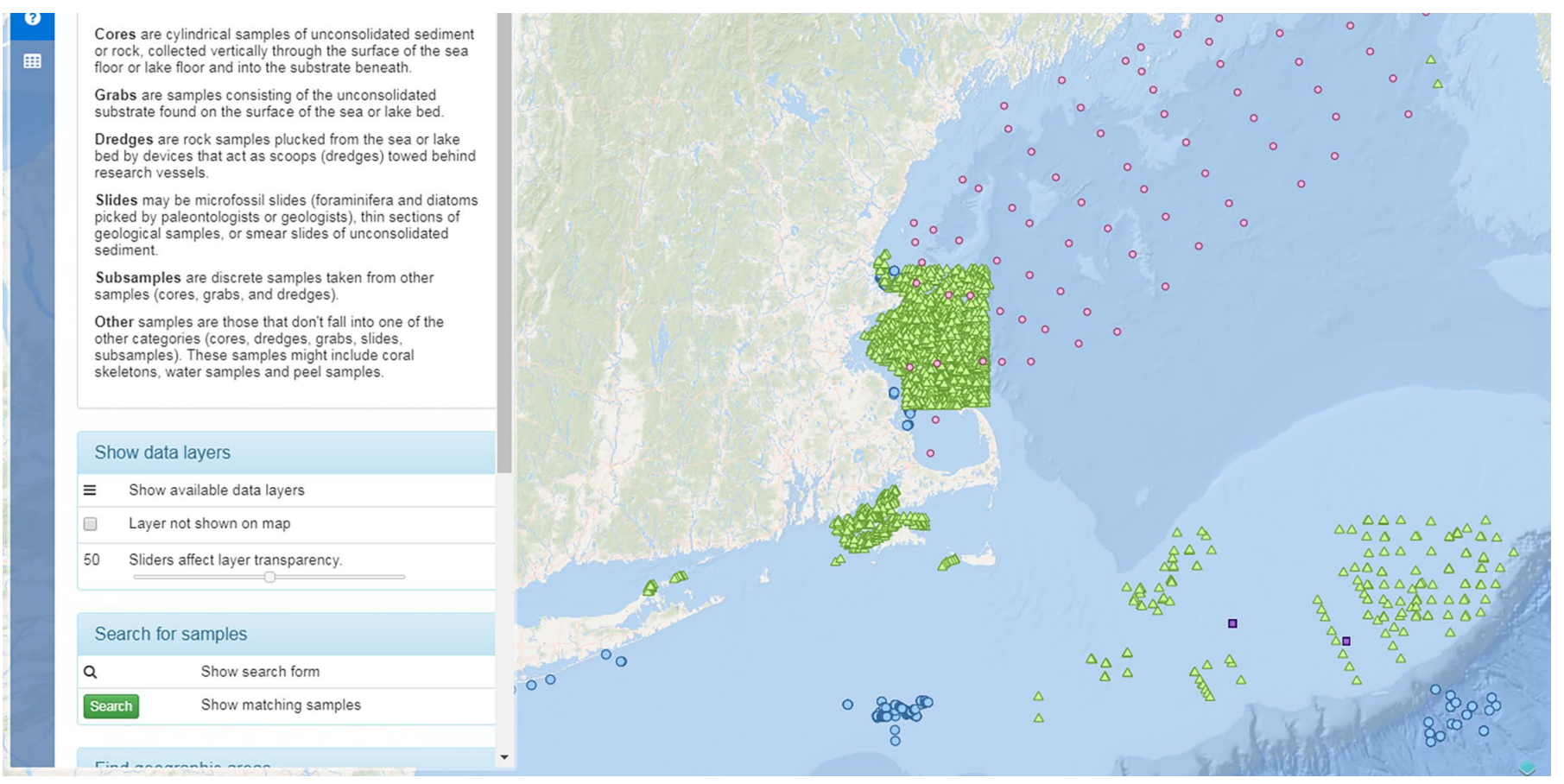

Figure 6. Screen capture showing geographic information system interface available to search the collections inventory for the U.S. Geological Survey Woods Hole Coastal and Marine Science Center Samples Repository (Buczkowski and others, 2018). 
Table 2. U.S. Geological Survey Woods Hole Coastal and Marine Science Center Samples Repository collections inventory search fields and their definitions.

\begin{tabular}{|c|c|}
\hline Search field & Explanation \\
\hline Platform & $\begin{array}{l}\text { Search by platform name or vessel used to collect } \\
\text { the samples. }\end{array}$ \\
\hline Scientist & $\begin{array}{l}\text { Search by the name, or partial name, of the prici- } \\
\text { pal investigator or collecting scientist. }\end{array}$ \\
\hline Activity & $\begin{array}{l}\text { Search by the field activity number assigned to } \\
\text { the cruise. }\end{array}$ \\
\hline Sample type & Select from a list of sample types available. \\
\hline Device & Select from a list of collection devices. \\
\hline Date collected & Select dates by using the calendar picker. \\
\hline
\end{tabular}

documented and tracked. Onsite resampling visits are initiated through these sample request forms; access to the Samples Repository facilities is coordinated through the Curator.

The Samples Repository maintains that PIs, collecting scientists, and project researchers have exclusive use of all samples and scientific collections for the tenure of the original project for which they were collected. For this reason, sample requests are evaluated in consultation with project PIs, if they are available, to determine the status of their research and the availability of associated samples.

\section{Notification of Request Status}

All sample requests are addressed upon their receipt and the individual initiating the request is notified by email regarding the status of their request and of the samples' availability. Once the request has been approved, the Curator completes and distributes a Sample Loan Agreement form, which the requesting individual signs and returns to the Samples Repository before any sample material is made available.

\section{Conditions of an Approved Loan}

By signing the Sample Loan Agreement form, the requesting individual acknowledges the following conditions and assures that they will be met during the duration of the loan. The Curator will return a copy of the Sample Loan Agreement form to the individual making the request after the sample request has been approved.

\section{Term of Loan}

All samples loaned out for research, along with any data derived from the analysis of these samples, will be returned to the Samples Repository at the borrower's expense, no later than the agreed upon due date stated at the top of the Sample
Loan Agreement form, or within one week after an earlier return is requested by the Curator.

\section{Use of Samples and Scientific Collections}

Samples on loan are for the sole use of the person or persons stated on the Sample Loan Agreement form. The borrower will not loan, deliver, lease, or transfer the samples to any other group or entity. When displaying the samples or publishing the results of any resultant research, the borrower will clearly state that these samples belong to the USGS and give proper credit to the source of the sample.

\section{Alteration of Samples}

In the sample request web form or email correspondence, the requester should clearly explain all proposed tests and anticipated alterations planned for the samples while they are in the borrower's care. Requests may be negotiated or denied if there is not enough sample material for the intended analyses. Samples on loan should be used only for the research and data extraction purposes stated on the Sample Loan Agreement form. If further analyses are needed, please contact the Curator.

\section{Loss or Damage}

The Samples Repository recognizes that many analytical methods are destructive in nature. However, unless it is agreed that the sample or any part of it will not be returned to the Samples Repository after analysis, the borrower is responsible for reporting any damage or loss of material to the Curator upon return of the samples.

\section{Commitment to Long-Term Preservation}

Samples and scientific collections fulfilling the 4-point standard that are accepted and inventoried into the Samples Repository are the responsibility of the PI or collecting scientist, in cooperation with the Curator. These samples and scientific collections will be cared for and available for reuse indefinitely. Should storage conditions change or space considerations arise, it is the duty of the WHCMSC Center Director and Curator, in consultation with the PI or collecting scientist, if available, to locate alternate storage solutions for the samples. Alternate storage locations may be at another USGS facility, or in an appropriate repository outside the USGS. Final authorization for any transfer of custody of scientific collections to repositories outside the Bureau must come from USGS Associate Directors. 


\section{Transfer of Custody to the National Museum of Natural History}

The Sundry Civil Act of March 3, 1879 (20 U.S.C. 59), as amended, directs that

All collections of rocks, minerals, soils, fossils, and objects of natural history, archaeology, and ethnology, made by the National Ocean Survey, the United States Geological Survey, or by any other parties for the Government of the United States, when no longer needed for investigations in progress shall be deposited in the National Museum. (20 USC §59)

The National Museum, specifically the Smithsonian Institution National Museum of Natural History (NMNH), has been designated as the ultimate repository for all scientific samples and scientific collections collected by the USGS and other Federal agencies and deemed appropriate for permanent retention. If samples that have already been accepted into the Samples Repository are evaluated and decisions are made to remove samples from the custody of the USGS due to storage limitations, duplication of sample material, or if samples are determined to no longer meet the USGS scientific mission, the Curator is bound to offer these samples to the NMNH for permanent transfer into the Smithsonian Institution's collections as a right of first refusal. If the NMNH declines the offer to accept the samples into their custody, the WHCMSC Center Director and Curator, in consultation with PIs, collecting scientists, and appointed WHCMSC advisors, will give due diligence to locating alternate storage and determine the final disposition for these samples by following the guidelines shown in figure 5 .

\section{Collections Management Across the U.S. Geological Survey}

The USGS has been collecting samples for research and analysis since its formation in 1879 . These samples and scientific collections represent the scientific legacy of the USGS and are an invaluable resource for further study and investigations. It is the responsibility of USGS scientists and managers to preserve the scientific integrity of these samples and scientific collections to meet the USGS scientific mission (U.S. Geological Survey, 2009).

Following the establishment of the USGS National Geological and Geophysical Data Preservation Program (NGGDPP) in the Energy Policy Act of 2005 (Public Law 109-58, Sec. 351), the USGS NGGDPP undertook the task of developing a uniform way to manage these collections, ensure their preservation, and ensure access to them by forming the Geologic Materials Repository Working Group, an assembly of researchers and collections managers charged with formulating a collections management plan that would be comprehensive and adaptable in order to accommodate the varied types of collections throughout the USGS. This working group produced USGS Circular 1410, "The U.S. Geological Survey Geologic Collections Management System (GCMS) - A Master Catalog and Collections Management Plan for the USGS Geologic Samples Collections" (Geologic Materials Repository Working Group, 2015), which proposes a set of collections management policies and procedures that can be applied to all USGS scientific collections. The collections management policies and procedures documented in this report were developed with the recommendations and resources provided in the GCMS in mind.

\section{The USGS Collections Steering Committee}

Following the publication of USGS Circular 1410, the USGS established a national governing body to advise USGS leadership and management on establishing scientific policies and protocols for the management of USGS scientific collections, as well as interfacing with local USGS Science Centers, researchers, and curators to facilitate the implementation of these policies. The USGS Collections Steering Committee (CSC), chartered in USGS Survey Manual Chapter 308.76 (U.S. Geological Survey, 2015), is this multidisciplinary governing organization charged with coordinating the management and stewardship of USGS scientific collections. The CSC is continuing to develop common vocabularies and common practices in collections management for implementation across the USGS, as well as promoting standards in databases and inventories for interoperability and access by the public.

\section{For More Information}

- U.S. Geological Survey Coastal and Marine Geoscience Data System (CMGDS): https://cmgds.marine. usgs.gov/

- Woods Hole Coastal and Marine Science Center Samples Repository: https://woodshole.er.usgs.gov/ operations/ia/samprepo/

\section{References Cited}

Buczkowski, B.J., Cross, V.A., and Schweitzer, P.N., 2018, Collections inventory for the U.S. Geological Survey Woods Hole Coastal and Marine Science Center Samples Repository: U.S. Geological Survey data release, https://doi.org/10.5066/F7319TT0. 
Geologic Materials Repository Working Group, 2015, The USGS Geologic Collections Management System (GCMS) - A master catalog and collections management plan for the USGS Geologic Samples Collections: U.S. Geological Survey Circular 1410, 108 p. [Also available at https://dx.doi.org/10.3133/cir1410 ].

Hopkins, T.L., 1964, A survey of marine bottom samplers: Progress in Oceanography, v. 2, p. 213-256.

List, K.M., Buczkowski, B.J., McCarthy, L.P., and Orton, A.M., 2015, Collections management plan for the U.S. Geological Survey Woods Hole Coastal and Marine Science Center Data Library: U.S. Geological Survey Open-File Report 2015-1141, 16 p., accessed September 22, 2017, at https://dx.doi.org/10.3133/ofr20151141.
U.S. Geological Survey, 2009, Geology Discipline research records schedule: U.S. Geological Survey Manual 432-1S5, accessed September 22, 2017, at https://www.usgs.gov/ usgs-manual/schedule/432-1-s5/gd.html.

U.S. Geological Survey, 2015, USGS Collections Steering Committee: U.S. Geological Survey Manual chapter 308.76, accessed September 22, 2017, at https:/www2.usgs.gov/ usgs-manual/300/308-76.html. 


\section{Glossary}

4-point standard The minimum standard information needed to evaluate samples and collections for acceptance into the Samples Repository: sample number assigned in the field (what), geographic location of field station (where), collector (who), and date collected (when).

accept To formally receive a sample or collection into the custody of the Samples Repository and incorporate it into the inventory.

barcode A code in the form of numbers, which can be human- as well as machinereadable, and a pattern of parallel lines of varying width which can be read by an optical laser scanner. Barcodes are affixed to samples and sample containers to identify their contents.

catalog The act of classifying objects into categories and documenting them with descriptive detail and identifying or descriptive unique numbers.

collecting scientist The researcher who was present for the sample collection in the field and who is responsible for recording any pertinent details, such as the location from which the sample was taken. This researcher may be the principal investigator, but is not always the same person (see principal investigator).

collection Research assets gathered together during the course of field work or scientific study and assembled according to a rational scheme, such as a common research project, principal investigator, or sample type. The Samples Repository manages samples in scientific collections, which are classified into institutional collections, legacy collections, and working collections based on their purpose, physical condition, and potential for use in further scientific investigations (see institutional collection, legacy collection, scientific collection, and working collection).

collections management The ongoing process of acquiring and maintaining a collection. It involves defining the policies and procedures that govern sample handling, labeling, storage, cataloging, conservation, and access.

curator Individual responsible for the organization, preservation, and maintenance of sample collections and inventories.

D-tube A tube-shaped container, usually some sort of plastic, used to store sediment cores that have been split longitudinally. This container is usually semicircular to accommodate the split cylinder of the core and resembles the capital letter " $D$ " in shape.

data library A facility that provides access to and retrieval of data and data-derived products.

disposition The outcome of the collection evaluation process that determines if a collection, or portion thereof, is to be transferred, or disposed of in accordance with applicable Bureau requirements.

field activity Any activity sponsored by and tracked by the U.S. Geological Survey (USGS) Coastal and Marine Geology Program for the purpose of collecting data and making observations in the field.

field activity number A unique identifying number assigned by data managers in the USGS Coastal and Marine Geology Program to track a field activity and link it to any samples, data, and derived records to which it is associated.

geographic information system (GIS) A system designed to capture, store, manipulate, analyze, manage, and present all types of spatial or geographical data.

institutional collection A collection of samples determined to have long-term scientific value to the USGS and preserved to ensure their scientific integrity and availability for future scientific research and to verify analytical results. Institutional collections are housed appropriately for long-term preservation and storage, inventoried, labeled, made accessible to all qualified users, and made available on request to qualified parties through formal loan procedures for research and education. These collections are re-evaluated periodi- 
cally to determine if all or a portion of the collection continue to possess scientific integrity and remain essential to the USGS research mission (see scientific collection).

inventory A complete list of samples and scientific resources available from a repository.

legacy collection A suite of samples collected by a research scientist who is no longer with the USGS, or collected as part of past research projects. Additional investigation may or may not be required to determine the minimum standard information needed to evaluate these samples and collections, reclassify them as institutional collections, and accept them into the Samples Repository (see institutional collection and scientific collection).

metadata Documentation about a sample or collection that describes pertinent background information, including field information (original geographic location, collector, date, sample identification number), the nature of the material, and any associated descriptive characteristics.

peel sample A sample derived from a split sediment core. Peel samples are generated by applying an adhesive to the cut surface of a split core and backing that adhesive with a flexible screen or other suitable material. Once the adhesive has dried, the backing is peeled back, removing the adhesive as well as the surface of the split core that was in contact with the adhesive.

policy A guiding principles designed to influence and determine decisions and actions.

preservation Various steps necessary to care for geoscientific data and collections, including data acquisition, organization, and maintenance; promoting user awareness of samples and data; ensuring data accessibility; and assurance that the data are useful and of sufficient quality. principal investigator (PI) The researcher responsible for the collection of the samples and the research performed on them.

procedure An established action or method for implementing policy.

repository A facility that assumes responsibility for the long-term management of scientific collections.

sample Any material collected for research purposes as a representative example of the field location.

sample name Alphanumeric identifier (ID) assigned to an individual sample to differentiate it from other samples in its collection group. Different IDs may accrue to the same sample as a result of processing performed by various analytical labs.

sample type A categorization of samples based on the general method used to collect or obtain them. Samples collected in the field are divided into the categories of "cores," "grabs," "dredges," and "other." The Samples Repository also maintains collections of derived samples, categorized as "subsamples" and "slides."

scientific collection Collections that are used for research, resource management, education, and other scientific purposes. Management and preservation of scientific collections is determined by their evaluation and classification, either as institutional or working collections (see institutional collection and working collection).

working collection A suite of samples being used actively for scientific research. Samples in working collections are subject to consumptive analysis and not initially intended for long-term preservation due to their expendable nature. Working collections that have long-term scientific value to USGS research beyond their original purpose will be evaluated to determine their potential to be reclassified as institutional collections and accepted in the Samples Repository (see institutional collection and scientific collection). 
For more information about this report, contact:

Director, Woods Hole Coastal and Marine Science Center U.S. Geological Survey

384 Woods Hole Road

Quissett Campus

Woods Hole, MA 02543-1598

WHSC_science_director@usgs.gov

(508) 548-8700 or (508) 457-2200

or visit our website at

https://woodshole.er.usgs.gov

Publishing support provided by the Pembroke Publishing Service Center 


\section{$\frac{\mathbb{2}}{3}$}

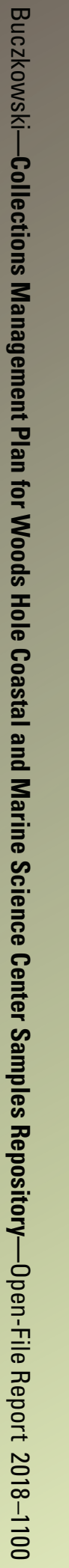

